\title{
Flexible AC transmission systems: A status review
}

\author{
K R PADIYAR and A M KULKARNI \\ Department of Electrical Engineering, Indian Institute of Science, \\ Bangalore, India 560012 \\ e-mail: krpyar@ee.iisc.ernet.in
}

\begin{abstract}
With the availability of high power semiconductor switches with turn-off capability, voltage source converter based controllers for power transmission system applications have become a reality. Prototypes of some second generation Flexible AC Transmission System (FACTS) controllers like TCSC and STATCON have been installed. This paper presents a review of the progress in FACTS. A generalized description of FACTS controllers is also presented.
\end{abstract}

Keywords. Flexible AC transmission systems; static condenser; unified power flow controller; thyristor controlled series compensation.

\section{Introduction}

Expansion in power transmission networks has taken place not only due to the increase in generation and loads but also due to the extensive interconnection among different power utilities. The major factor for system interconnection is the economy possible in the reduced generation reserves for achieving the same level of reliability of supply.

Except for the limited number of HVDC links in a system, the vast majority of transmission lines are AC. The power flows in AC lines are uncontrolled and are determined by Kirchhoff's laws. This is in contrast to HVDC links where the power flow has to be regulated by converter controls. The lack of control in AC networks can be considered an advantage from the point of view of avoiding additional equipment. However AC lines have the following disadvantages.

(1) Power flow in parallel paths is determined according to their reactance. As a first approximation, the power flow in AC networks can be compared to the power flow in DC resistive networks where the resistance is analogous to the reactance. The operation of KVL (Kirchhoff's voltage law) implies that the network is often not optimally utilized.

(2) Power flow in AC lines (except short lines of lengths below $150 \mathrm{~km}$ ) is limited by stability considerations. This implies that the lines may operate normally only at power levels much below their thermal limits. 
(3) The operation of KVL and lack of control in AC lines implies that the normal power flow in a line is kept much below the peak value which itself is limited by stability (as mentioned earlier). This margin (or reserve) is required to maintain system security under contingency conditions.

(4) The AC transmission network requires dynamic reactive power control to maintain satisfactory voltage profile under varying load conditions and transient disturbances.

(5) AC lines, while providing synchronizing torque for oscillating generator rotors may contribute negative damping torque which results in undamped power oscillations, (particularly with fast acting static exciters and high gain automatic voltage regulators).

(6) The increase in load levels is accompanied by higher reactive power consumption in the line reactances. In case of mismatch in the reactive power balance in the system, this can result in voltage instability and collapse.

The reactive power compensation of $\mathrm{AC}$ lines using fixed series or shunt capacitors can solve some of the problems associated with AC networks. However the slow nature of control using mechanical switches (circuit breakers) and limits on the frequency of switching imply that faster dynamic controls are required to overcome the problems of $\mathrm{AC}$ transmission networks. Recent developments involving deregulation and restructuring of the power industry are aimed at isolating the supply of electrical energy (a product) from the service, involving transmission from generating stations to load centres. This approach is feasible only if the operation of AC transmission lines is made flexible by introducing fast-acting high-power solid state controllers using thyristor or GTO valves (switches). The advent of high voltage and high power thyristor valves and digital controllers in HVDC transmission has demonstrated the viability of deploying such controllers for power transmission. Thyristor controllers were also utilized in the late seventies to control current in reactors and switch capacitors and this led to the development of Static Var Compensators (SVC).

Flexible AC Transmission System (FACTS) is a concept proposed by Hingorani $(1988,1991,1993)$ that involves the application of high power electronic controllers in AC transmission networks which enable fast and reliable control of power flows and voltages. FACTS do not indicate a particular controller but a host of controllers which the system planner can choose, based on cost benefit analysis. The objectives are as below.

(1) Regulation of power flows in prescribed transmission routes.

(2) Secure loading of lines nearer their thermal limits.

(3) Prevention of cascading outages by contributing to emergency control.

(4) Damping of oscillations which can threaten security or limit the usable line capacity.

Table 1 shows that the controllers can be broadly classified into two classes:

(a) shunt-connected controllers providing voltage control;

(b) series-connected controllers providing power flow control. 
Table 1. FACTS controllers.

\begin{tabular}{|c|c|c|c|c|}
\hline Name & Type & Main function & Controller used & Comments \\
\hline SVC (static var compensator) & Shunt & Voltage control & Thyristor & $\begin{array}{l}\text { Variable impedance } \\
\text { device }\end{array}$ \\
\hline $\begin{array}{l}\text { TCSC (thyristor controlled } \\
\text { series compensation) }\end{array}$ & Series & $\begin{array}{l}\text { Power flow } \\
\text { control }\end{array}$ & Thyristor & $\begin{array}{l}\text { Variable impedance } \\
\text { device }\end{array}$ \\
\hline $\begin{array}{l}\text { TCPAR (thyristor controlled } \\
\text { phase angle regulator) }\end{array}$ & $\begin{array}{l}\text { Series } \\
\text { and shunt }\end{array}$ & $\begin{array}{l}\text { Power flow } \\
\text { control }\end{array}$ & Thyristor & $\begin{array}{l}\text { Phase control using } \\
\text { series (quadrature) } \\
\text { voltage injection }\end{array}$ \\
\hline STATCON (static condenser) & Shunt & $\begin{array}{l}\text { Voltage } \\
\text { control }\end{array}$ & GTO * & $\begin{array}{l}\text { Variable voltage } \\
\text { source }\end{array}$ \\
\hline $\begin{array}{l}\text { SSSC (static synchronous } \\
\text { series compensator) }\end{array}$ & Series & $\begin{array}{l}\text { Power flow } \\
\text { control }\end{array}$ & $\begin{array}{l}\text { GTO * } \\
\text { source }\end{array}$ & Variable voltage \\
\hline $\begin{array}{l}\text { UPFC (unified power flow } \\
\text { controller) }\end{array}$ & $\begin{array}{l}\text { Shunt } \\
\text { and series }\end{array}$ & $\begin{array}{l}\text { Voltage and } \\
\text { power flow } \\
\text { control }\end{array}$ & GTO * & $\begin{array}{l}\text { Variable voltage } \\
\text { source }\end{array}$ \\
\hline
\end{tabular}

* Note: Instead of the GTO, other power semiconductor devices with turn-off capability such as IGBT or MCT (MOS controlled thyristors) can also be used.

TCPAR provides power flow control mainly by injecting a quadrature voltage in series. The complex power generated by the series voltage source is supplied by the shuntconnected transformer. The simplified expression for power flow in a lossless transmission line is given by

$$
P=\frac{V_{S} V_{R} \sin \left(\delta_{S R}+\phi\right)}{X},
$$

where $V_{S}$ and $V_{R}$ are sending and receiving end bus voltages, $X$ is the series reactance of the line, $\delta_{S R}$ is the difference in the bus angles, $\phi$ is the phase angle shift introduced by a phase angle regulator (phase shifting transformer).

It is obvious from (1) that the control of voltage, series reactance and phase angle $(\phi)$ affects the power flow. While the control over the first two variables can be used to increase the power limit, the control over $\phi$ can be used to regulate power flow in loops.

Thyristor controllers have also been employed or proposed for the following.

(a) Subsynchronous Resonance (NGH) damping (Hingorani 1981).

(b) Thyristor Controlled Dynamic Brake (Rao \& Nagsarkar 1984; Raschio et al 1995).

(c) Fault Current Limiting (Salama et al 1993; Sugimoto et al 1996).

(d) Overvoltage Protection (Sarkozi et al 1994).

FACTS controllers have also been proposed in distribution systems for control of power quality (Larsen et al 1992; Hingorani 1995; Akagi 1996; Sabin \& Sundaram 1996). The objectives are to limit voltage fluctuations and reduce the impact of momentary interruptions that would affect sensitive loads. In addition, distribution type FACTS devices can be used to eliminate harmonics and voltage flicker introduced by nonlinear loads that would affect other loads in the proximity. 
In this paper, the state of the art in the development of FACTS is presented. The attention is focussed on the new FACTS controllers based on voltage source converters (STATCON and UPFC).

\section{Description of FACTS controllers}

In this section we briefly describe the basic principle of operation of some of the FACTS controllers.

\subsection{Static Var compensator}

SVC is an important FACTS device already widely in operation. Ratings range from 60 MVAR to 600MVAR. SVC can be considered as a "first generation" FACTS controller and uses thyristor controllers. It is a shunt reactive compensation controller (Gyugyi 1979, 1988; Miller 1982) consisting of a combination of fixed capacitor or thyristor-switched capacitor in conjunction with thyristor-controlled reactor (FC-TCR or TSC-TCR) (figure 1). The SVC is a variable susceptance controller; the effective susceptance is varied by changing the conduction time of the thyristors of the TCR and/or switching in/out the shunt capacitor using a TSC. Early applications of the SVC were for load compensation of fast-changing loads like arc furnaces and steel mills for dynamic power factor improvement and load balancing in the three phases. Transmission line compensators are used not only for reactive power compensation (maintaining voltages at key points of the network within limits) but also for improving system stability. The control strategy usually employed is to use the SVC as a voltage regulator. In addition supplementary controls are used for damping power oscillations. The steady state control characteristics of a SVC is shown in figure 2 . In the controllable range, a small slope is given to the characteristic to prevent frequent hitting of limits and also to facilitate parallel operation.

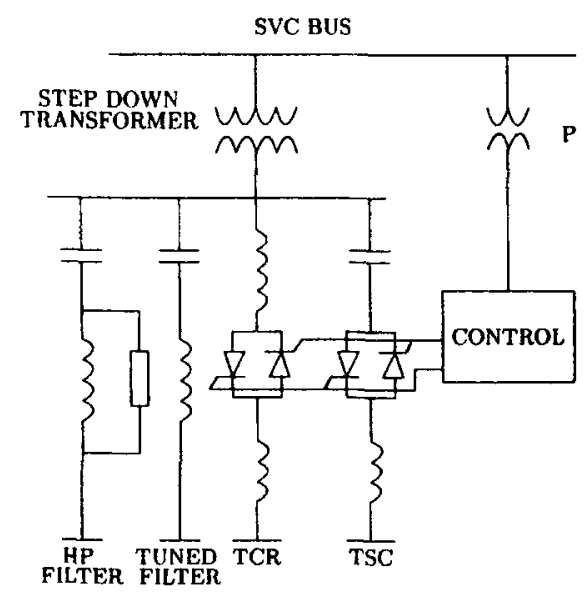

Figure 1. TCR-TSC type SVC. 


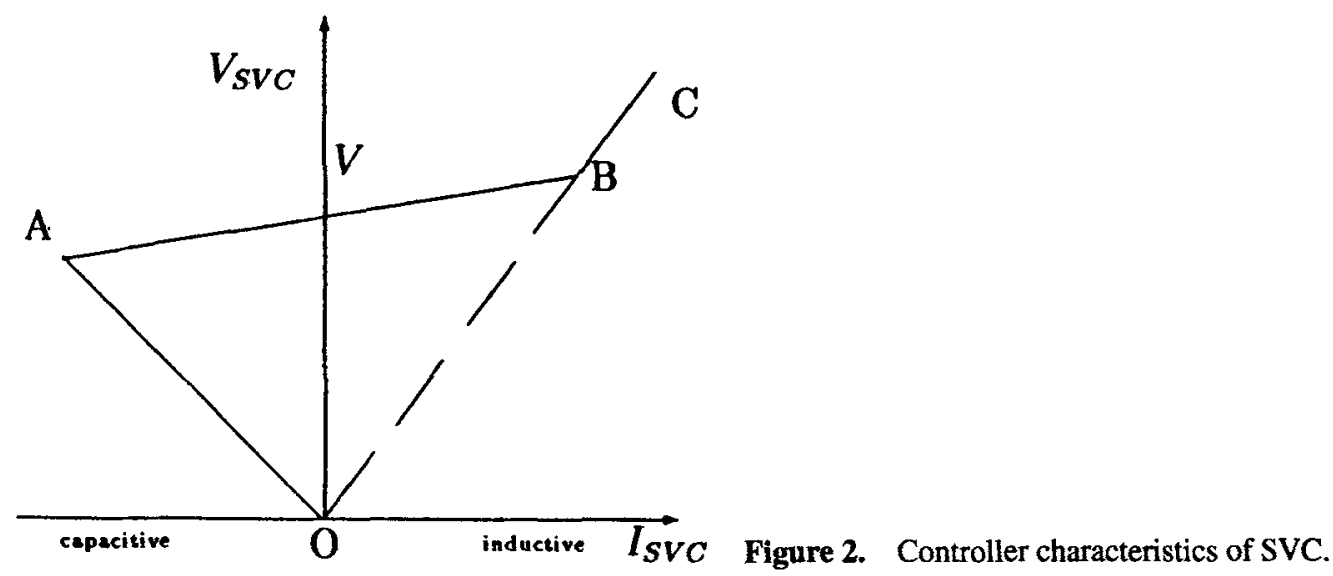

\subsection{Thyristor-controlled series compensator}

The TCSC is a second generation FACTS controller which controls the effective line reactance by connecting a variable reactance in series with the line. The variable reactance is obtained using a FC-TCR combination with mechanically switched capacitor sections in series. Figure 3 shows a TCSC with two modules connected in series. Use of series compensation is usually a preferable alternative for increasing power flow capability of lines as compared to shunt compensators as the ratings required for series compensators are significantly smaller. Use of TCSC can reduce the adverse torsional interactions with generator-turbine shafts ("Subsynchronous Resonance") which is a major concern in the application of series capacitors.

The first demonstration project of TCSC was commissioned in 1991 at a $345 \mathrm{kV}$ Kanawha River Substation in West Virginia, USA under American Electric Power Company. This was a test installation of thyristor switches in one phase for rapid switching of series capacitor segments and was supplied by Asea Brown Boveri, Sweden.

In October 1992, the first three-phase TCSC was installed at $230 \mathrm{kV}$ Kayenta Substation in Arizona under the Western Area Power Administration (WAPA) (Christl 1991). Here a $15 \Omega$ capacitor bank is connected in parallel with a TCR and permits smooth and rapid control of (capacitive) reactance between 15 and $60 \Omega$ through phase control of TCR ( $\alpha$ varying between 145 to 180 ).

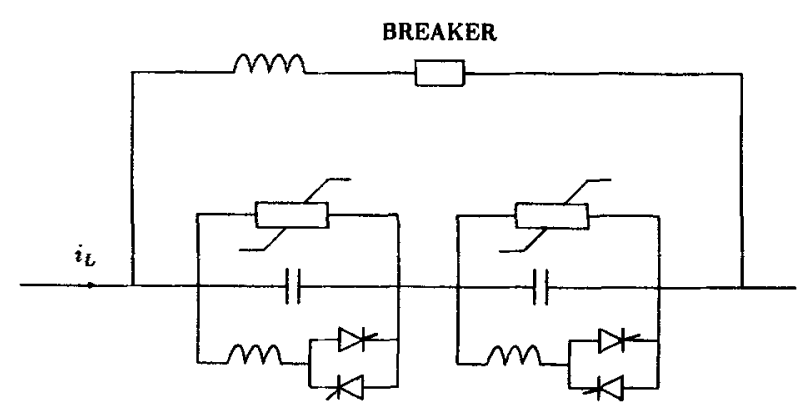

Figure 3. Single line diagram of TCSC. 


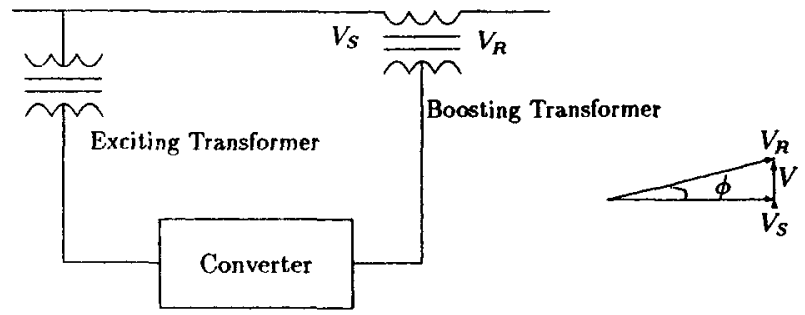

Figure 4. Static phase shifter schematic.

A large prototype three-phase TCSC was installed in 1993 at $500 \mathrm{kV}$ Slatt Substation in Oregon under the Bonneville Power Administration (BPA) (Urbanek et al 1993; Piwko et al 1994). The project was sponsored by the Electric Power Research Institute (EPRI) and the equipment was developed by General Electric in U.S.A. Here, six modules of TCSC are connected in series and controlled to provide a variation in impedance from $+1.4 \Omega$ to $-16 \Omega$.

\subsection{Thyristor-controlled phase angle regulator}

This is also known as Static Phase Shifter (SPS) and phase shift with respect to the bus voltage is achieved by adding or subtracting a variable voltage component in quadrature with the bus voltage. This variable quadrature voltage component in one phase is obtained by thyristor switches and by an exciting transformer which is connected between the other two phases. The quadrature voltage is injected in series with the transmission line by a boosting transformer. The basic arrangement is shown in figure 4 .

Many configurations of the SPS have been proposed (some employing GTOs). Also, with some configurations continuously variable phase angle of injected voltage (not necessarily in quadrature) is achievable. For a description of available topologies for SPS and a comparison between them see the review by Iravani \& Maratukulam (1994).

\subsection{STATCON}

STATCON is a shunt reactive compensation device; however, unlike the SVC it is based on voltage source converter (VSC) using GTOs (figure 5). The principle of operation is similar to that of a synchronous condenser. The VSC is connected to the system through a small reactance which is the leakage reactance of the coupling transformer. The VSC produces a set of three phase voltages which are in phase with the corresponding bus voltages. The reactive power is varied by varying the magnitude of the converter output voltages. A small phase difference exists in the steady state (depending on reactive power output) so that real power can be drawn from the lines to compensate for the losses. The current on the $\mathrm{DC}$ side is mainly a ripple of magnitude much smaller than the AC line currents. As no real energy exchange (except to compensate for losses) takes place in steady state, the DC voltage can be maintained by a capacitor.

The STATCON can also exchange active power with the system if it has an energy source at its DC terminals. In this situation, the phase of the inverter output voltages with respect to corresponding bus voltages is varied to obtain control over active power. 


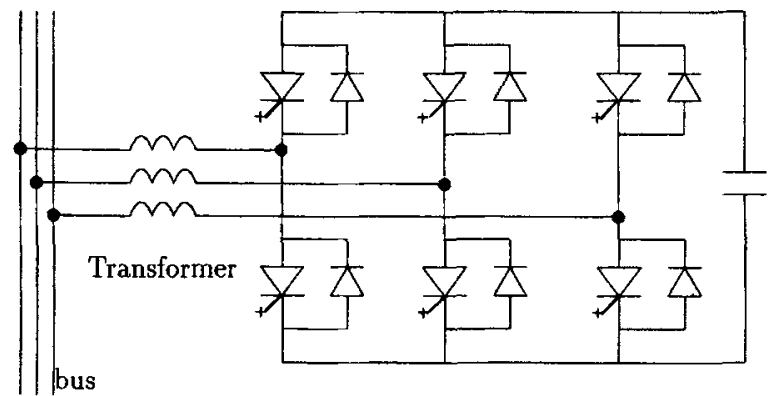

Figure 5. Six-pulse STATCON.

The major advantages of the STATCON over the SVC are (Edwards et al 1988; Larsen et al 1992):

(1) The STATCON can supply required reactive current even at low values of bus voltage, whereas the reactive current capability of SVC at its susceptance limit decreases linearly with decrease in bus voltage (compare figures 2 and 6).

(2) With proper choice of device ratings and thermal design, STATCON can have a short time overload capability. This is not possible in an SVC because there is an inherent susceptance limit.

(3) Significant size reduction can be achieved because of reduced number of passive components and their smaller size.

(4) STATCON can allow for real power modulation if it has an energy source or large energy storage at its DC terminals.

An early application of a \pm 20 MVAR STATCON (Sumi et al 1981) used forced commutated thyristors. Subsequently there have been GTO based installations which include a \pm 1 MVAR (Edwards et al 1988) and a larger \pm 80 MVAR (Mori et al 1993) STATCON. A large \pm 100 MVAR prototype installation has been reported recently (Schauder et al 1995). Some of the salient features of this STATCON are as follows.

(1) 48-pulse inverter ( 8 inverters connected in series on the AC side with appropriate phase shifts and in parallel on the DC side).

(2) DC capacitor voltage: $6.6 \mathrm{kV}$.

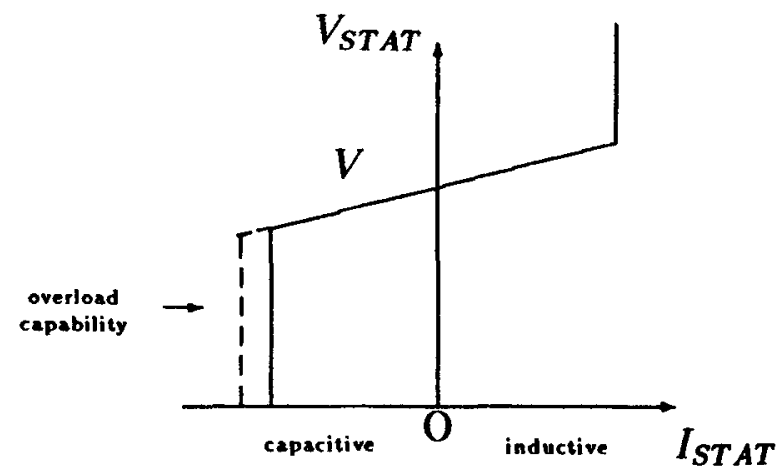

Figure 6. Control characteristics of STATCON. 
(3) Inverter valves employ 5 GTO modules in series.

(4) GTO rating: $4500 \mathrm{~V}, 4000 \mathrm{~A}$ (peak turn-off).

A bidirectional 18-pulse voltage source converter utilizing GTOs and rated at $10 \mathrm{MVA}$ was reported (Walker 1990). The converter is rated to operate in all four quadrants and connects a storage battery to a utility grid. It can be used for static Var control, as a power system stabilizer or as a real power peaking station.

In addition to multipulse topology, multilevel converter topology has also been proposed for the STATCON (Menzies \& Zhuang 1995; Ekanayaki \& Jenkins 1996). However the optimum circuit configuration is difficult to choose because relative significance of design parameters will vary from application to application.

\subsection{Unified power flow controller (UPFC)}

The UPFC (Gyugyi 1992, 1994, 1995) is the most versatile of FACTS controllers. The main function of the UPFC is to control real and reactive power flow through the line by injection of a (variable) voltage in series with the transmission line. A schematic of the UPFC is shown in figure 7. The UPFC consists of 2 GTO-based inverter branches. The series branch consists of a voltage source inverter which injects a voltage in series through a transformer. Since the series branch of the UPFC can inject a voltage with variable magnitude and phase angle it can exchange real power with the transmission line. However the UPFC as a whole cannot supply or absorb real power in steady state (except for the power drawn to compensate for the losses) unless it has a power source at its DC terminals. Thus the shunt branch is required to compensate (from the system) for any real power drawn/supplied by the series branch and the losses. In addition the shunt branch can exchange reactive power independently with the system. Thus the UPFC offers three controllable parameters. If only the series branch of the UPFC is used, there is only one controllable parameter which is the magnitude of the injected voltage (the phase of the injected voltage is constrained to be in quadrature with the line current so that the device cannot supply or absorb real power). This device is called the Static Synchronous Series Compensator (SSSC).

The world's first demonstration of a UPFC is under installation by American Electric Power Co., at the utility's Inez Station in eastern Kentucky, USA. It is to be installed in two phases; the $\pm 160 \mathrm{MVAr}$ shunt inverter has been installed first for voltage support in 1997. Subsequently, the series inverter of the same rating will be installed. The converter will use GTOs and a three-level topology.

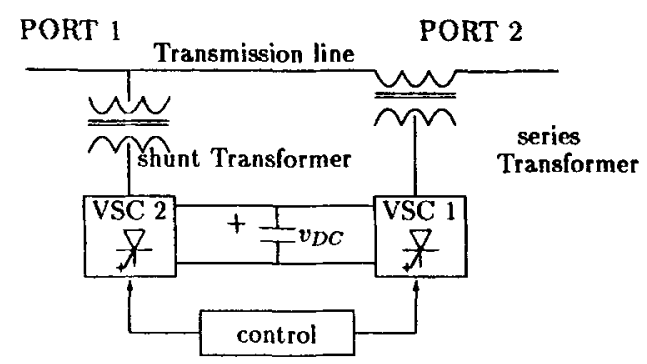

Figure 7. UPFC. 


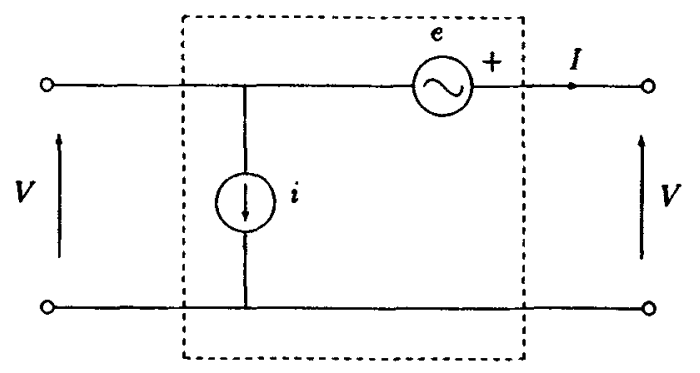

Figure 8. Circuit representation.

\subsection{Generalized description}

Based on the treatment given by Gyugyi (1992), the influence of a FACTS controller in a transmission line can be viewed as injection of a shunt current source and a series voltage source (see figure 8). This is the most general description of a FACTS controller, such as a UPFC.

Ignoring active power losses in the controller, the following constraint equation applies

$$
\operatorname{Re}\left[V i^{*}\right]=\operatorname{Re}\left[e I^{*}\right]
$$

It is assumed that both $e$ and $i$ are sinusoidal and can be expressed as phasors in steady state. Equation (2) shows that there are three independant variables (for example, magnitude and phase angle of $e$ and the value of reactive component of current in $i$ ) that can be manipulated to control power flows (active and reactive) in a line.

It is to be noted that the general case, a FACTS controller may contain an energy source and thus even the constraint equation (2) does not apply. However this is unlikely except in the case of STATCON which may use a battery energy storage system for providing electrical energy during interruptions caused by system faults.

Except for UPFC, most of the FACTS controllers use only single control variable as listed in table 2.

Table 2. Mathematical description.

\begin{tabular}{lll}
\hline Controller & Constraint equations & Control variable \\
\hline SVC & $e=0, i=j B_{S V C V} V$ & $B_{S V C}$ \\
TCSC & $i=0, e=j X_{T C S C} I$ & $X_{T C S C}$ \\
TCPAR & $V i=e I$ & $\phi$ \\
& $V=V e$ & $i$ (reactive current) \\
STATCON & $e=0, \operatorname{Re}\left[V i^{*}\right]=0$ & $i_{a}$ (active current) \\
$\quad$ without energy source & $e=0$ & $i$ \\
$\begin{aligned} \text { STATCON } \\
\quad \text { with energy source }\end{aligned}$ & $i=0, \operatorname{Re}\left[e I^{*}\right]=0$ & $e$ (reactive voltage) \\
SSSC &
\end{tabular}

Note: SSSC is a special case of UPFC when only the series element is used. 


\section{Control of STATCON and UPFC}

\subsection{STATCON control}

The primary controller of the STATCON is the reactive current (component of current in quadrature with the bus voltage) controller. A closed-loop control of reactive current is necessary because the STATCON current is dependent not only on the firing angle of the GTOs but also on the parameters of the rest of the system as well.

There are two controller structures which have been proposed for reactive current control of STATCON (Schrouder \& Mehta 1993).

(1) Type I: The controller uses both magnitude and phase angle control of the voltage controllers to control the real and reactive current (figure 9). The real current is used to maintain capacitor at a constant voltage. The reactive current can be used as an inner loop of a bus voltage regulator. The real current is used to maintain capacitor voltage constant.

(2) Type II: Reactive current control can also be achieved by phase-angle control alone. The capacitor voltage is not controlled but depends upon the phase difference between the converter output voltages and the bus voltage (the phase difference is usually very small). Thus the converter voltage magnitude (which is dependent on the capacitor magnitude alone in this case) varies with phase angle. As a result, control over reactive current is possible by phase control. Control of bus voltage is achieved as in type I type controller (figure 10).

PI control of STATCON (type II) poses problems due to nonlinearity in the state equations. Nonlinear state feedback control is used to overcome this problem by Schrauder \& Mehta (1993). Fuzzy logic control (which can be thought of as nonlinear heuristic control) has also been used in (Padiyar \& Kulkarni 1997) and shows superior performance under varying system conditions. Control of STATCON for reducing overcurrents during unbalanced faults using PWM has been discussed by Jiang \& Ekstrom (1995). In the design of control systems, the possibility of adverse interactions with the network and/or other FACTS controllers in the vicinity has to be kept in mind (Clark et al 1995; Woodford 1996). The problem of network-controller interactions has been reported in the voltage control of STATCON (Padiyar \& Kulkarni 1997) which is solved by filtering the voltage signal.

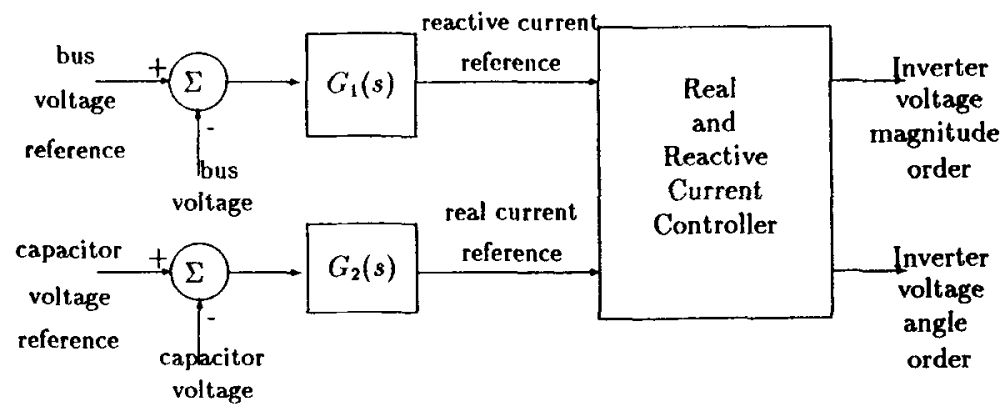

Figure 9. Type I type controller. 


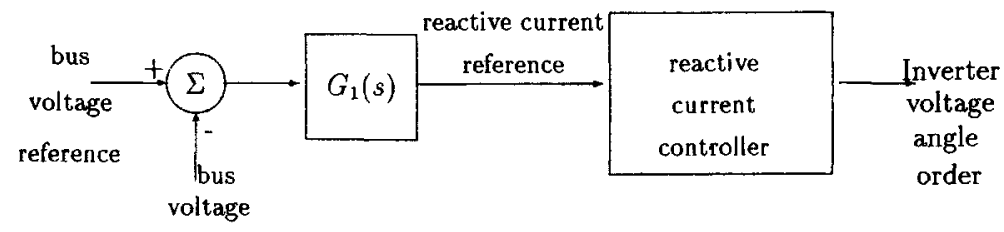

Figure 10. Type II type controller.

\section{$3.2 \quad U P F C$ control}

The UPFC allows three controllable parameters, viz., magnitude and phase of series injected voltage, and shunt reactive current. A control strategy for UPFC has been proposed (Padiyar \& Kulkarni 1996) in which active power flow through the line is controlled, while regulating magnitudes of the voltages at its two ports.

The controller for this purpose uses only local measurements. The series voltage of the UPFC is split into two parts, one in phase with the line current ("real voltage") and the other in quadrature ("reactive voltage"). Series reactive voltage is used to control active power flow in the line, while real voltage and shunt reactive current injection are used to regulate voltage at the two ports. A block diagram representation of the series voltage controller is shown in figure 11. The power controller sets the reactive voltage reference. An auxiliary current angle stabilizing signal is used to damp a critical network mode associated with series reactance of line (steady state contribution of this auxiliary signal is zero because of the washout block $\left.\left[s T_{w} /\left(1+s T_{w}\right)\right]\right)$. A damping controller for the slow electromechanical modes of the system associated with generator rotor swings modulates the power reference, and uses the generator slip signal. A synchronising component $(K / s)$ is present in the controller in addition to the damping component $(D)$ to reduce angle deviations. The real voltage to be injected can be calculated so as to maintain port 2 voltage magnitude of the UPFC constant. The voltage and power references can be set

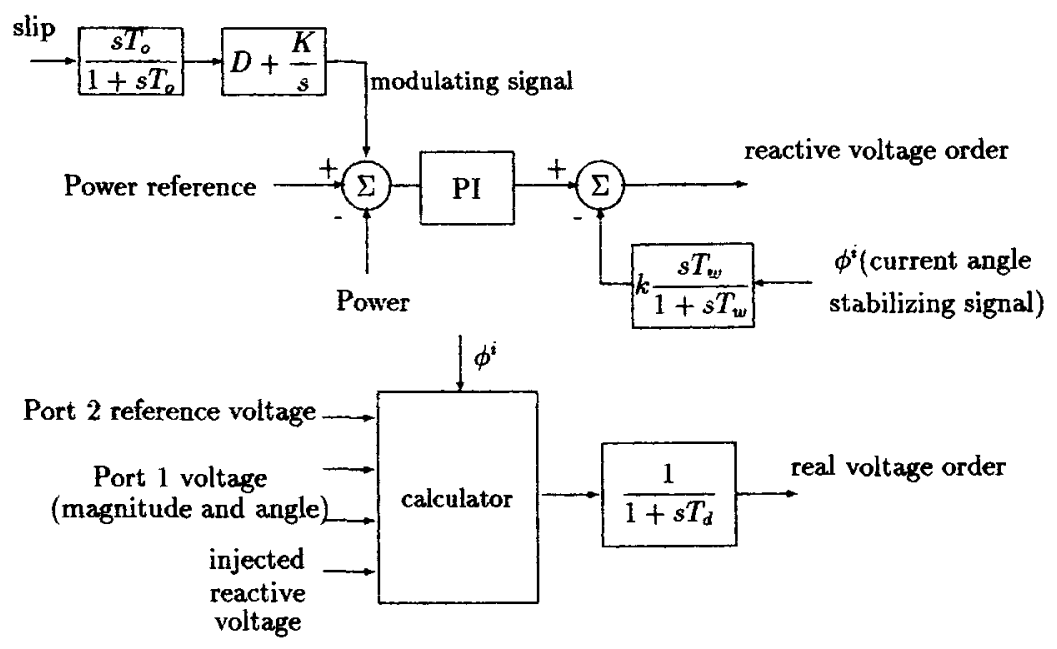

Figure 11. UPFC series voltage controller structure. 
according to steady state real and reactive power flow requirements. The shunt current controller is similar to the one shown in figure 9.

\section{Stability improvement using FACTS controllers}

The fast response of FACTS controllers can be used effectively to improve dynamic performance of the system. The dynamic problems associated with power systems can be characterised as (Padiyar 1996):

(1) Angle instability: which includes small signal oscillatory instability ("dynamic instability") and large disturbance instability leading to loss of synchronism amongst generators ("transient instability"). These problems are associated with generator rotor swings.

(2) Voltage instability: which implies an uncontrolled collapse in voltage at load buses precipitated due to some disturbance and is primarily caused by dynamics of the load.

(3) Subsynchronous resonance (SSR): This problem is caused by the adverse interaction of the electrical system with the generator-turbine mechanical system causing oscillatory instability or transient torques. This problem is usually present in radial series compensated lines connected to turbine generators.

While the application of FACTS controllers for steady state active and reactive power flow control is relatively straightforward, their use for stability improvement poses the following questions:

(1) Where should the controllers be located in the system for maximum effectiveness?

(2) What should be the control laws?

Usually FACTS controllers are used for steady state functions which is the main control objective, but supplementary controls are included for stability improvement. However, controllers such as Thyristor Controlled Brake (Rao \& Nagsarkar 1984: Raschio et al 1995) and NGH-SSR damper (Hedin et al 1981; Hingorani 1981; Hingorani et al 1987; Benko et al 1987) are used specifically for transient stability improvement and SSR mitigation respectively. It should be kept in mind that the control strategy employed will vary from application to application depending on the relative severity of the various dynamic and steady state problems.

For SVCs, while voltage control is the main function, Supplementary Modulation Controller (SMC) can be introduced for damping small signal oscillations. This controller modulates either the voltage reference of the voltage controller or the susceptance. A typical configuration of SMC is shown in figure 12. A washout block is used to drive SMC output to zero in steady state. Similar control structures can be used for TCSC.

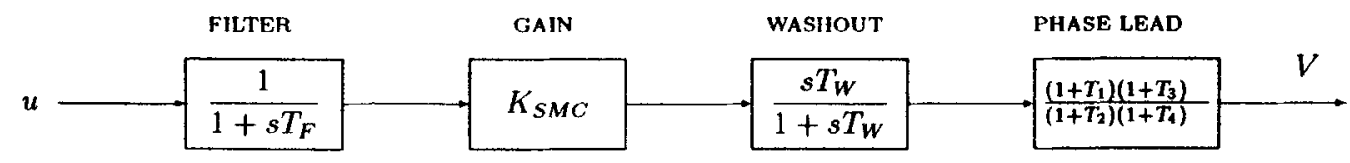

Figure 12. Supplementary modulation controller. 
Methods proposed in literature for deciding location of FACTS controllers and control strategies (choice of control signal ( $u$ in the SMC) and the corresponding control law) are based mainly on eigenvalue sensitivity/residue (of transfer function) approaches (Padiyar et al 1986; Martins \& Lima 1990; Okamato et al 1995). Computation of several indices has been proposed (Larsen et al 1995) to select the appropriate control signal and control law. Control strategies have also been proposed based on energy function approach (Gronquist et al 1995).

Study of large disturbance dynamics involves analysis of a large set of nonlinear differential equations. Design of control strategies and deciding on the best location from the point of view of transient stability improvement is a difficult problem and has to be validated using simulation studies. Large disturbance stability improvement with FACTS controllers has been shown using simulation studies (see for example Mihaltic et al 1996). Discrete control strategies have been proposed by Kosterev \& Kolodziej (1995) and Padiyar \& Uma Rao (1997).

The problem of torsional interactions (SSR) has been a major concern, primarily because some FACTS controllers like SVC have the potential to cause adverse interations, even in the absence of series compensation (Rustomkolai et al 1990). Therefore thorough studies need to be done in order that FACTS controllers themselves do not aggravate this problem. Studies on application of TCSC and field tests indicate that SSR problem can be reduced with it (see Piwko et al 1996). It is possible (FACTS controllers can have time of response of the order of 1-3 cycles) that supplementary controls be introduced to damp SSR directly. Use of auxiliary signals to damp SSR has been proposed for SVCs (see Ramey et al 1981, Wascjnczuk 1981, Putman \& Ramey 1982, Hammad \& El-Sadek 1984, Abi Samra et al 1985, Padiyar \& Varma 1990). Further work needs to be carried out with new controllers such as STATCON, UPFC and SSSC.

\section{Conclusions}

The application of FACTS controllers throws up new challenges for power engineers, not only in hardware implementation, but also in design of robust control systems, planning and analysis.

There has been considerable progress in the application of FACTS controllers. Notably, prototypes of TCSC and STATCON of sufficiently high ratings are now in operation. Implementation of several other controllers such as UPFC are being planned. Field experiences with these installations are eagerly awaited by power engineers.

The new generation of FACTS controllers are voltage source converter-based and have several advantages over thyristor-controlled variable impedance type controllers. However, these controllers require switching devices with turn-off capability. At present, only GTO devices are available at the voltage and current ratings required. These devices have certain drawbacks and it is anticipated that in future, better and more efficient devices like IGBT and MCT will be available in the required ratings. Spurred by demand, the cost of these devices is also expected to come down.

There is every reason to believe that in a decade or so, FACTS controllers will revolutionize electrical power transmission systems making them more reliable, optimally utilized and better controlled. 


\section{References}

Akagi $\mathrm{H} 1996$ New trends in active filters for power conditioning. IEEE Trans. Ind. Appl. 32: $1312-1322$

Abi Samra N C, Smith R F, McDermott T E, Chidester M B 1985 Analysis of thyristor controlled shunt SSR countermeasures. IEEE Trans. Power Apparatus Syst. 104: 584-597

Benko I S, Bhargava B, Rothenbuler W N 1987 Prototype NGH subsynchronous resonance damping scheme. Part II - Switching and short circuit tests. IEEE Trans. Power Syst. 12: 1040-1049

Clark K, Fardanesh B, Adapa R 1995 Thyristor controlled series compensation application studyControl interaction considerations. IEEE Trans. Power Delivery 10: 1031-1037

Christl N, Hedin R, Johnson R, Krause P, Montoya A 1991 Power system studies and modelling for Kayenta $230 \mathrm{kV}$ substation. Advanced series compensation. In Fifth Int. Conf. on AC and DC Transmission London, IEE Conf. Publ. No. 345: 33-37

Ekanayake J B, Jenkins N 1996 A three level advanced static var compensator. IEEE Trans. Power Delivery 11: 540-545

Edwards C W, Nannery P R, Mattern K E, Stacey E J, Gubernick J 1988 Advanced static var generator employing GTO thyristors. IEEE Trans. Power Delivery 3: 1622-1627

Gronquist J F, Sethares W A, Alvarado F L, Lasseter R H 1995 Power oscillation damping strategies for FACTS devices using locally measurable quantities. IEEE Trans. Power Syst. 10: $1598-1605$

Gyugyi L 1979 Reactive power generation and control using thyristor circuits. IEEE Trans. Ind. Appl. 15: 521-531

Gyugyi L 1988 Power electronics in electrical utilities: Static var compensators. Proc. IEEE 76: 482-594

Gyugyi L 1992 Unified power flow control concept for flexible AC transmission systems. Inst. Elec. Eng. Proc. C139: 323-331

Gyugyi L 1994 Dynamic compensation of AC transmission lines by solid state synchronous voltage sources. IEEE Trans. Power Delivery 9: 904-911

Gyugyi L 1995 The unified power flow controller: A new approach to power transmission control. IEEE Trans. Power Delivery 10: 1085-1099

Hammad A E, El-Sadek M 1984 Application of a thyristor controlled VAR compensator for damping subsynchronous oscillations in power systems. IEEE Trans. Power Apparatus Syst. 103: $198-212$

Hingorani N G 1981 A new scheme for subsynchronous resonance damping of torsional oscillations and transient torque - Part I. IEEE Trans. Power Apparatus Syst. 100: 1852-1855

Hingorani N G 1988 Power electronics in electrical utilities: Role of power electronics in future power systems. Proc. IEEE 76: 481-482

Hingorani N G 1991 FACTS-Flexible AC transmission systems. In Fifth Int. Conf. on AC and DC Transmission, London IEE Conf. Publ. No. 345: 1-7

Hingorani N G 1993 Flexible AC transmission systems IEEE Spectrum 30: 40-45

Hingorani N G 1995 Custom power IEEE Spectrum 32: 41-48

Hingorani N G, Bhargava B, Garrigue G F, Rodriguez G D 1987 Prototype NGH subsynchronous resonance damping scheme-Part I - Field installation and operating experience. IEEE Trans. Power Syst. 12: 1034-1039

Hedin R A, Stump K B, Hingorani N G 1981 A new scheme for subsynchronous resonance damping of torsional oscillations and transient torque - Part II. IEEE Trans. Power Apparatus Syst. 100: 1856-1863 
Iravani M R, Maratukulam D 1994 Review of semiconductor controlled phase shifters for power system applications. IEEE Trans. Power Syst. 9: 1833-1839

Jiang Y, Ekstrom A 1995 Applying PWM to control overcurrent at unbalanced faults of force commutated voltage source converters used as static var compensators. In Stockholm Power Technol. Conference, Stockholm, Sweden, pp 18-22

Kosterev D N, Kolodziej W J 1995 Bang-bang series capacitor transient stability. IEEE Trans. Power Syst. 10: 915-923

Larsen E V, Leonard D J, Miller N W, Othmann H, Paserba J J, Naumann S J 1992 Application studies for a distribution STATCON on commonwealth Edison's power system. In Proceedings of FACTS Conference, Electric Power Res. Inst. (EPRI), Boston

Larsen E V, Miller N, Nilsson S, Lindgren S 1992 Benefits of GTO-based compensation systems for electric utility application. IEEE Trans. Power Delivery 7: 2056-2064

Larsen E V, Sanchez-Gasca J J, Chow J H 1995 Concept for design of FACTS controllers to damp power swings. IEEE Trans. Power Syst. 10: 948-956

Miller T J E 1982 Reactive power control in electric systems (New York: John Wiley)

Martins N, Lima L T G 1990 Determination of suitable location for power system stabilizers and static var compensators for damping electromechanical oscillations in large scale systems. IEEE Trans. Power Syst. 5: 1455-1469

Mori S, Matsuno K, Hasegawa T, Ohnishe S, Takeda M, Seto S, Murakami S, Ishiguro F 1993 Development of large static var generator using self-commutated inverter for improving system stability. IEEE Trans. Power Syst. 8: 371-377

Menzies R W, Zhuang Y 1995 Advanced static compensation using multilevel GTO inverter. IEEE Trans. Power Delivery 10: 732-737

Mihalic R, Zunko P, Povh D 1996 Improvement of transient stability using unified power flow controller. IEEE Trans. Power Delivery 11: 485-491

Okamato H, Kurita A, Sekine Y 1995 Method for identification of effective locations of variable impedance apparatus on enhancement of steady state stability in large scale power systems IEEE Trans. Power Syst. 10: 1401-1407

Padiyar K R 1996 Power system dynamics - Stability and control (Bangalore: Interline)

Padiyar K R, Kulkarni A M 1997 Design of reactive current and voltage controller of static condenser. Int. J. Elect. Power Energy Syst. to appear

Padiyar K R, Kulkarni A M 1996 Development and evaluation of controls for unified power flow controller. In Ninth National Power Systems Conference, Indian Institute of Technology Kanpur, pp 253-257

Putman T H, Ramey D G 1982 Theory of modulated reactance solution for subsynchronous resonance. IEEE Trans. Power Apparatus Syst. 101: 1527-1535

Padiyar K R, Rajashekharam P, Radhakrishnan C, Pai M A 1986 Dynamic stabilization of power systems through reactive power modulation. Elect. Mach. Power Syst. 11: 281-293

Padiyar K R, Uma Rao K 1997 Discrete control of series compensation for stability improvement of power system. Int. J. Elec. Power Energy Syst. 19: 311-319

Padiyar K R, Varma R K 1990 Static var system auxiliary controllers for damping torsional oscillations. Int. J. Elec. Power Energy Syst. 12: 271-286

Piwko R J, Wegner C A, Furumasu B C, Damsky B L, Eden J D 1994 The Slatt thyristor controlled series capacitor project: Design, installation, commissioning and system testing. Int. Conf. Large High Voltage Electric Systems (CIGRE), Paris, 14-104

Piwko R J, Wegner C A, Kinney S J, Eden J D 1996 Subsynchronous resonance performance tests of the slatt thyristor controlled series capacitor. IEEE Trans. Power Delivery 11: 1112-1119 
Ramey D G, Kimmel D S, Dorney J W, Kroening F H 198 I Dynamic stabilizer verification tests at the San Juan station. IEEE Trans. Power Apparatus Systems 100: 5011-5019

Raschio P, Mittelstadt W A, Haner J F, Spee R, Enslin J H R 1995 Evaluation of dynamically controlled brake for western power system. In CIGRE 1995 Symposium on Power Electronics in Electric Power Systems, Tokyo, pp 22-24

Rao C S, Nagsarkar T K 1984 Half wave thyristor controlled dynamic brake to improve transient stability. IEEE Trans. Power Apparatus Syst. 103: 1077-1083

Rostomkolai N, Piwko R J, Larsen E V, Fischer D A, Mobarak M A, Poitras A E 1990 Subsynchronous torsional interaction with SVCs - Concepts and practical implications. IEEE Trans. Power Syst. 5: 1324-1332

Sabin D D, Sundaram A 1996 Quality enhances. IEEE Spectrum 33: 34-41

Salama M M A. Temraz H, Chikhani A Y, Bayoumi M A 1993 Fault current limiter thyristor controlled impedance. IEEE Trans. Power Delivery 8: 1518-1528

Sarkozi M, Gyugyi L, Bronfeld J D, Nilsson S, Damsky B 1994 Thyristor switched ZNO voltage limiter. Proc. of Int. Conf. Large High Voltage Electric Systems (CIGRE), Paris, 14-302

Schauder C, Gernhardt M, Stacey E, Cease T W, Edris A, Lemak T, Gyugyi L 1995 Development of \pm 100 Mvar static condenser for voltage control of transmission systems. IEEE Trans. Power Delivery 10: 1486-1496

Schauder C, Mehta H 1993 Vector analysis and control of advanced static var compensator. Inst. Elec. Eng. Proc. C 140: 299-306

Sumi Y, Harumoto Y, Hasegawa T, Yano M, Ikeda K, Matsuura T 1981 New static var control using force commutated inverters. IEEE Trans. Power Apparatus Syst. 100: 4216-4224

Sugimoto S, Kida J, Arita H, Fukui C, Yamagiwa T 1996 Principle and characteristics of a fault current limiter with series compensation. IEEE Trans. Power Delivery 11: 842-847

Urbanek J, Piwko R J, Larsen E V, Damsky B L. Furumasu B C, Mittelstadt W, Eden J D 1993 Thyristor controlled series compensation prototype installation at the $500 \mathrm{kV}$ Slatt substation. IEEE Trans. Power Delivery 8: 4460-4469

Walker L 1990 A 10 MW GTO converter for battery peaking service. IEEE Trans. Ind. Appl. 26: 63-72

Wasynczuk O 1981 Damping subsynchronous resonance using reactive power control. IEEE Trans. Power Apparatus Syst. 100: 1096-1104

Woodford D A 1996 Electromagnetic design considerations for fast acting controllers. IEEE Trans. Power Delivery 11: 1515-1521 